Simón Castellano, Pere, Justicia cautelar e inteligencia artificial. La alternativa a los atávicos heurísticos judiciales, J. M. Bosch Editor, Barcelona, 2021, 260 pp., ISBN 978-84-123154-0-0.

\author{
http://dx.doi.org/10.18543/ed-69(2)-2021pp347-352
}

De acuerdo con la Real Academia Española, «autómata» es, entre varios usos del término, la persona que actúa sin reflexión. La definición conlleva cierta paradoja porque, según la etimología griega y latina del término

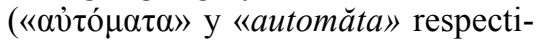
vamente), el uso histórico de la palabra, recogido en la literatura clásica, estaba circunscrito a la máquina, ingenio o artilugio que operaba de forma individual, emulando en cierto sentido a los seres vivos.

De este modo, el automatismo no se vincula hoy, en nuestro imaginario, únicamente a la artificiosidad como realidad contraria a la naturaleza, sino que se hace extensivo a aquel proceso que obedece a una serie de reglas de forma ciega (o «muda», parafraseando a la lectura ilustrada del poder judicial según Montesquieu).

Así pues, el concepto no es privativo de la tecnología, sino que es plenamente aplicable al ser humano cuando este se comporta de acuerdo con la misma lógica. $\mathrm{Al}$ autor de la monografía reseñada no se le escapa esta observación, pues ya bien entrados en el capítulo II, afirma que los seres humanos somos «automáticos, recurrentes, en una mayor medida de lo que podemos pensar, en nuestro día a día, en nuestro actuar cotidiano».

Pues bien, la justicia, y en concreto la justicia cautelar que es objeto de estudio y reflexión en la presente obra, se encuentra en la encrucijada de tener que respetar la seguridad jurídica $y$, al mismo tiempo, no caer en el «apodíctico automatismo» operante en ciertos actos procesales de indudable relevancia constitucional, de acuerdo con el autor y la rica doctrina científica que cita.

Es aquí precisamente donde debemos detenernos y deshacernos de ciertos apriorismos antes de continuar con la lectura, pues si hemos dicho que el automatismo se manifiesta también en un hardware de carne y hueso, la suspicacia humanista que se nos despierta cuando escuchamos la conjunción del concepto de justicia e inteligencia artificial debería evaporarse o, al menos relativizarse.

Y debería relativizarse porque la crítica debe centrarse en los procesos formales que cometen o devienen en injusticias, con independencia de que sean aplicados por operadores jurídicos humanos o artificiales. Además, como 
indica el autor de la obra, solo un iluso puede pensar que los algoritmos no acabarán tomando cierto protagonismo en el poder judicial, como ya está ocurriendo con la herramienta COMPAS en el mundo anglosajón, y que es objeto de análisis en la monografía.

Sin embargo, como bien advierte de forma sutil el autor en la cita preliminar, de las máquinas, más bien, habría que temer no su existencia, sino otro peligro, esto es, que no acaben erigiéndose en dictadores: «Tu eres mi creador, pero yo soy tu dueño: ¡obedece!». Frankenstein, como monstruo a caballo entre la Ilustración y el Romanticismo, ya nos advertía de los límites de la inteligencia artificial y las pretensiones endiosadas de la humanidad.

Hechas estas aclaraciones, estamos mejor equipados para disfrutar del estudio del Dr. Pere Simón, pues el lector tiene ante sí una obra que no solo ostenta calidad doctrinal desde un punto de vista jurídico (por lo que puede leerse con las formalidades pertinentes a golpe de notas, apuntes y referencias), sino que también puede devorarse en un ambiente distendido de reflexión, como una suerte de ensayo, para sumergirnos en una serie de cuestiones a las que a nadie le puede resultar ajeno.

La monografía se divide en tres partes: el derecho y los sistemas jurídicos en la encrucijada; prisión provisional e inteligencia artificial; y derechos, garantías y controles tangibles.

La primera sección se aproxima al derecho desde el contexto de la cuarta revolución industrial (las tecnologías de la información y la IA), pero lo hace desde una posición que evita los extremos «apocalípticos e integrados» a los que hace referencia el autor, citando el consejo de Umberto Eco. Desde esta perspectiva, que revela la sabiduría de los griegos de no caer en los extremos, al autor no se le escapan las potencialidades de las nuevas tecnologías, sin caer en la trampa del discurso ingenuo, tan de moda, de los oráculos del optimismo digital.

Por ello, quien suscribe las líneas de la monografía también nos advierte de ciertos peligros de la sociedad digital, de la «hiperpublicidad y la hiperaccesibilidad de la información», de la cultura «touch» de la inmediatez, de las exigencias de derechos sin sus correspondientes deberes. En este punto, el autor nos invita a aproximarnos a este fenómeno desde una perspectiva multidisciplinar y culta, analizando el derecho con buenos compañeros de viaje como la sociología, la psicología y la filosofía, así como otras disciplinas que permiten aproximarse al objeto de estudio desde un criticismo que enriquece la reflexión jurídica. No obstante, el autor no se olvida de Jellinek, y cita la necesidad de que, al fin y al cabo, al «derecho se llega mediante el derecho», lo que constituye el fin último de la monografía.

A estas reflexiones preliminares, se le añade la necesidad de abordar el fenómeno de la inteligencia artificial desde la tesis de acuerdo con la cual nada podrá escapar a sus algoritmos, por lo que los juristas no pueden (o no deberían) mirar hacia otro lado. De este modo, se plantea si los androides o los sistemas tecnológicos podrán emular el juicio jurisdiccional y, así, 
sustituir por completo al juez. No es cuestión baladí.

La hipótesis del autor es que la inteligencia artificial no podrá reemplazar el juicio jurisdiccional, pero podrá complementarlo para que el operador jurídico pueda sustraerse a las limitaciones epistemológicas del ser humano, a saber: los «atávicos heurísticos» a los que hace referencia el autor, entre los que se encuentra la intuición sesgada y el automatismo de copia y pega a la hora de emitir autos de prisión provisional.

Así pues, de acuerdo con el autor, sin sustituir al juez, la inteligencia artificial y las máquinas «sí pueden apoyarlo en la toma de decisiones que hoy se formulan en base a la experiencia $y$, necesariamente, tienen un germen subjetivo o valorativo, cuando no se formulan en base a emociones, sesgos u opiniones, ya sea en la libre valoración de la prueba o en escenarios tan concretos como la ponderación de los intereses fundamentales en juego a la hora de decidir la prisión provisional del investigado o la libertad condicional del preso».

La obra tampoco deja de lado la aplicación de la inteligencia artificial basada en macrodatos, puesto que, como señala el autor, el cerebro humano «es incapaz de valorar en décimas de segundo y tomar una decisión basada en las variables y probabilidades, pero la máquina sí». Esto puede tener beneficios en la aplicación de la ley, complementándola con la analítica predictiva servida de Big Data cuando la norma debe tener en cuenta el contexto y datos empíricos.

Ejemplo de ello, y que constituye el objeto principal y central de la monografía, a saber, la justicia cautelar manifestada en el instituto procesal de la prisión provisional, nos sitúa ya en la segunda parte de la obra. El Dr. Simón, que a estas alturas de la monografía ya nos ha acostumbrado a la reflexión multidisciplinar, pero sin perder la precisión de la especialidad, nos advierte de ciertos hechos:

«...los jueces no operan en el vacío. Ni pueden ni deben hacerlo. De hecho, ningún ser humano lo hace en su actuar cotidiano. Lo que sucede en el exterior nos condiciona, nos aflige y llega a afectar nuestra toma de decisiones. Es lo que Kahneman (2014), sobre lo que volveremos más adelante en breve, llama el efecto del contexto y enlaza con la afección y la emoción. O lo que fue, en su día, brillantemente expuesto por Chayes (1975), cuando nos advertía que el juzgador no puede actuar aislado del entorno social y las decisiones que este toma en los litigios de interés público son fruto de un diálogo natural, permanente e inevitable con otros elementos sociales y políticos - académicos, prensa, el poder ejecutivo, el legislador, agencias administrativas y el público, en general-».

Llegados a este punto, se nos advierte de un fenómeno crónico, pero que atenta gravemente contra ciertos principios del estado de derecho, como lo es la sobrecarga de los juzgados y tribunales, sobrecarga a la que el poder ejecutivo ha condenado al poder judicial, propiciando los copy\&paste en los autos y fundamentos jurídicos, así como otros atajos que favorecen el 
automatismo al que hacíamos referencia al inicio de esta reseña.

La riqueza de la monografía también se alimenta de la capacidad de observación del autor, a la que antaño nos acostumbró la antropología y la literatura decimonónica realista y naturalista, pero ya casi inexistente en el irreflexivo devenir de la hiperdigitalización de la sociedad de la inmediatez. De este modo, se nos advierte de:

«Una tendencia bifronte que inspira nuestro actuar desde bien pequeños. $\mathrm{Y}$ es precisamente cuando observamos el comportamiento de nuestros pequeños, de nuestros niños, que operan y piensan sin los límites de los marcos conceptuales que nos han o nos hemos (auto) impuesto, cuando nos damos cuenta cómo y hasta qué punto condicionan la toma de decisiones humanas esas dos circunstancias: fatiga y comodidad bien podrían estar detrás de la mayoría de las decisiones humanas. Una vez más, nada explicaría que el juzgador pudiera escapar a la premisa anterior».

Estos condicionantes, entre los que se enumeran las emociones; la ideología; la memoria y estadística prima facie (o «aquello que [respecto a los jueces] recuerdan y que les viene a la cabeza de forma casi automática sobre casos anteriores» según las teorías prospectivas de los psicólogos Tversky y Kahneman); la intuición; la fatiga, el anclaje... Todo estos sesgos heurísticos y epistemológicos son limitaciones humanas que podrían verse superadas, o al menos disminuidas, con el concurso y complemento de la inteligencia artificial.
De modo más específico, la monografía se pregunta cómo el Ministerio Fiscal y el juez instructor adoptan las peticiones y medidas cautelares respectivamente, en el contexto procesal de la vistilla del art. 505 de la LECr, considerando que, como señala el autor, se produce la siguiente paradoja: el instructor debe decidir «sin operar en el vacío - heurísticos, atajos intuitivos y efecto del contexto- pero operando stricto sensu en el más completo vacío - sin pruebas, sin conocer todas las variables en juego, a veces sin tan siquiera haber escuchado los argumentos de las partes-》.

Consideradas las limitaciones cognitivas de los operadores jurídicos, el autor aborda la inteligencia artificial judicial para la valoración del riesgo. En concreto, se estudia el software IAJVR y cómo este puede contribuir a la eficacia de los principios de idoneidad, necesidad y proporcionalidad, pues como se señala en la obra, este tipo de tecnología podría eliminar cualquier «vestigio de la afección y la emoción en la toma de decisiones, reduciendo las prácticas basadas en el anclaje y ajuste, en el automatismo de lo cómodo y práctico, objetivando stricto sensu, con un porcentaje real, el nivel del riesgo que se conjura y delimita teniendo en cuenta todas las variables del caso concreto y de sus precedentes».

En este punto el autor reflexiona sobre la importancia de las bases de datos, pues si estas son sesgadas, la inteligencia artificial también lo será. Recuérdese el caso de Amazon, en la que un algoritmo se encargaba de hacer el trabajo de recursos humanos, basándose en el histórico de contrataciones 
anteriores. El resultado fue desalentador: la perpetuación de un sesgo de género en la contratación de personal.

Esto nos debe advertir de que la evaluación del riesgo de reiteración delictiva, fuga o destrucción de pruebas, como fines constitucionalmente establecidos por el legislador para justificar las medidas provisionales de privación de libertad, y llevada a cabo por la inteligencia artificial, puede caer en los mismos sesgos heurísticos a los que se hacen alusión en la monografía respecto a la inteligencia humana. Una base de datos que no se sustraiga a los prejuicios sistémicos que campan en nuestro entorno social, tanto en los procesos de recolección, almacenamiento, procesamiento como de tratamiento, no puede generar una inteligencia artificial útil como complemento a la justicia, sino más bien un escenario distópico para alimentar la literatura de Huxley, Orwell, Bradbury o Dick.

Por último, la tercera parte aborda las garantías jurídico-constitucionales que deben tenerse presentes ante los retos tecnológicos, como el derecho de defensa y el principio de publicidad procesal. El autor se pregunta si el código del sistema IAJVR debe ser público. Sin duda una problemática similar ya ha sido objeto de análisis por la doctrina científica, especialmente en el campo del derecho administrativo, donde la publicidad de los sistemas que toman decisiones automatizadas está pendiente de juicio al momento de redactar estas líneas (caso del sistema BOSCO).

En el campo penal, la cognoscibilidad, publicidad, y transparencia del código fuente plantea los mismos problemas, si bien, como señala el autor, las exigencias en esta jurisdicción deberían ser mayores, especialmente considerando la entrada en juego del secreto de sumario, sin olvidarse de la reciente doctrina constitucional al respecto (STC 83/2019, de 17 de junio). De este modo, se concluye que el mencionado secreto de las comunicaciones no debería abarcar el secreto del código fuente, tomando en cuenta las exigencias constitucionales y normativas (entre otras, la Directiva 2012/13/UE, de 22 de mayo, sobre el derecho a la información en los procesos penales).

La tesis defendida aquí es de sumo interés, pues si bien en el campo del derecho administrativo la doctrina ha señalado la colisión entre el principio de transparencia y el de propiedad intelectual de los programadores, en el campo penal mantener el secreto sobre todos estos detalles del sistema de IA, según el autor, supone laminar el derecho de defensa del investigado «a cambio de nada».

Siguiendo esta línea argumental, el Dr. Simón indica que una conclusión como la alcanzada en la sentencia del Tribunal Supremo de Wisconsin en el asunto Wisconsin v. Loomis «es absolutamente inviable en nuestro modelo, tuitivo por naturaleza y definición». Y añade: «Que las decisiones y resoluciones judiciales puedan basarse en parte en valoraciones de riesgo realizadas mediante herramientas actuariales digitalizadas o incluso sistemas de IAJVR, es decir, IA stricto sensu, comercializadas por compañías privadas, cuyo funcionamiento no se revela al público ni al investigado o acusado porque se considera un secreto de empresa, es una auténtica aberración del 
sistema que constriñe el derecho de defensa».

Como puede observarse, la monografía también se nutre de la jurisprudencia de órganos jurisdiccionales no comunitarios, analizando así el devenir de la justicia y el impacto de las tecnologías de la información con casos reales y actuales. El lector se halla ante una obra completa que rehúye de consignas, tópicos o simplificaciones, por lo que, en la era del bombardeo de información, en la que estamos constantemente expuestos a webinars, post, prensa digital de consumo rápido, etc., la monografía ofrece un espacio sereno de reflexión al que cualquier jurista del s. XXI debería prestar atención.

Javier Dorado Ferrer

Coordinador del Grado en Derecho

ESERP Business \& Law School 


\section{Simón Castellano, Pere, Justicia cautelar e inteligencia artificial. La alternativa a los atávicos heurísticos judiciales, J. M. Bosch Editor, Barcelona, 2021, 260 pp., ISBN 978-84-123154-0-0.}

http://dx.doi.org/10.18543/ed-69(2)-2021pp347-352

\section{Copyright}

Estudios de Deusto es una revista de acceso abierto, lo que significa que es de libre acceso en su integridad. Se permite su lectura, la búsqueda, descarga, distribución y reutilización legal en cualquier tipo de soporte sólo para fines no comerciales, sin la previa autorización del editor o el autor, siempre que la obra original sea debidamente citada y cualquier cambio en el original esté claramente indicado

Estudios de Deusto is an Open Access journal which means that it is free for full access, reading, search, download, distribution, and lawful reuse in any medium only for non-commercial purposes, without prior permission from the Publisher or the author; provided the original work is properly cited and any changes to the original are clearly indicated. 